LUVOX Briet Summary of prescribing intormation (bosed on $8 E 1252$ Rev $3 / 97$ ) INDICATIONS AND USAGE

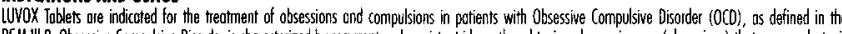

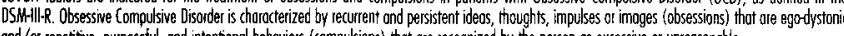
and/or repetinve, priposely,

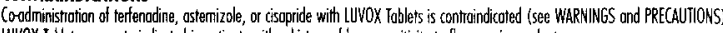

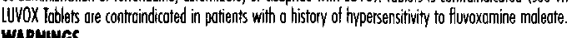

WARNAMGS

In potients receiving another seretonin reepptake inhbitior thug in combination with monoamine oxidase inhbititors (MAOls),

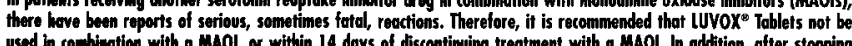
usad in coubination with o MAOI, or within 14 days of discontining treetment with a MAOI. In addition, affer stopping Ierfonodinte, ostemizote and cisepride ore ofl metabolized by the cytochrome P450IIIA4 isoenzyme. Increased plasmo

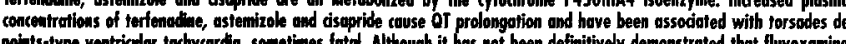

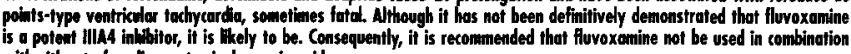

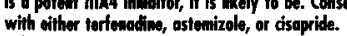

Other Potentiolly Importent Dreng Interections

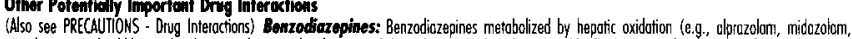

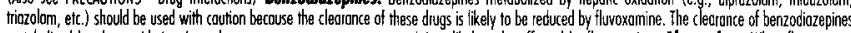

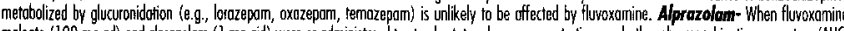

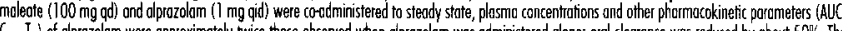

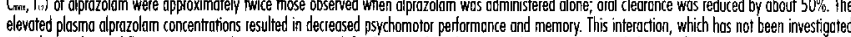

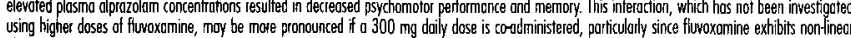

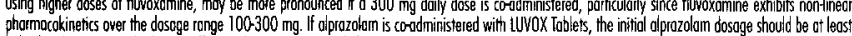

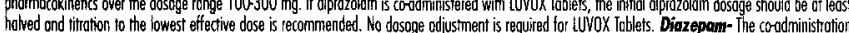

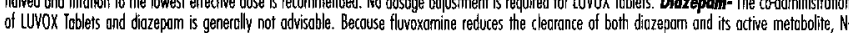

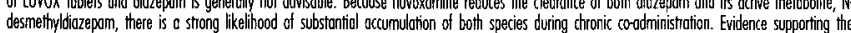

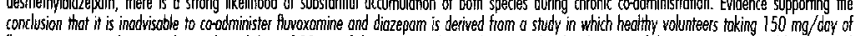

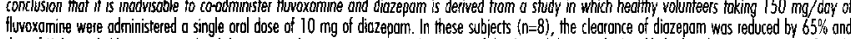

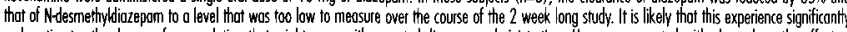

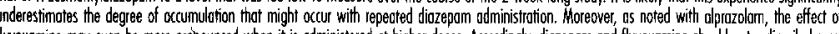

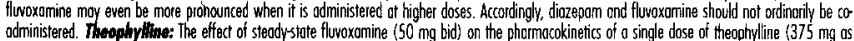

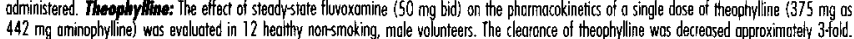

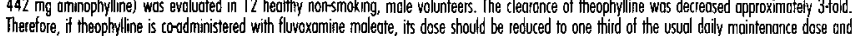

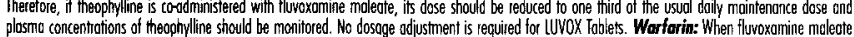

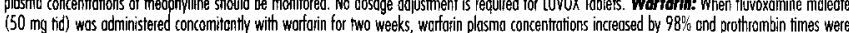

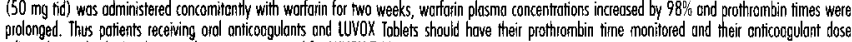

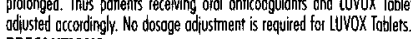

PRECAuTtons

Gomial

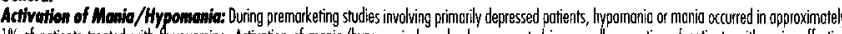

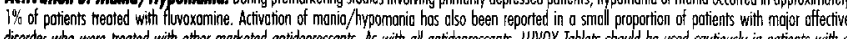

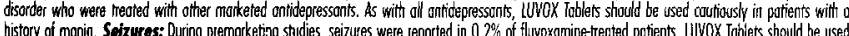

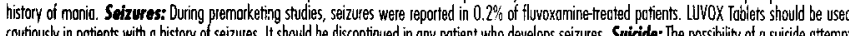

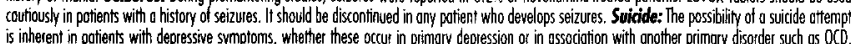

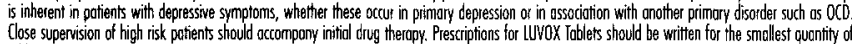

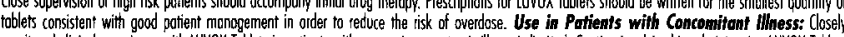

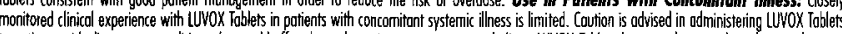

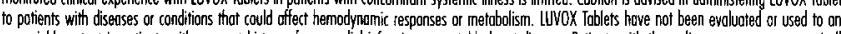

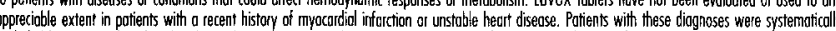

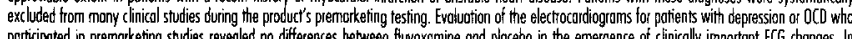

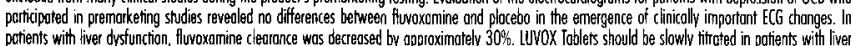

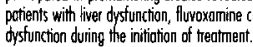

\section{Information for Pationts}

Physicins cre odvised to discuss the following issues with patients for whom they prescribe LWVOX Tablets: Interference with Cognifive or Motor

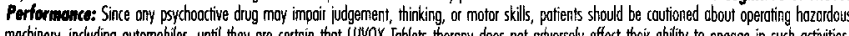

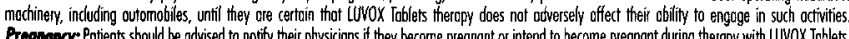

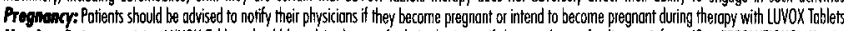

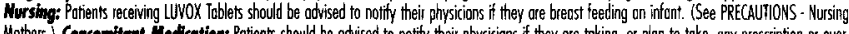

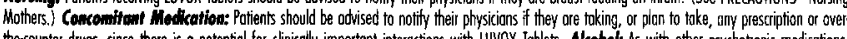

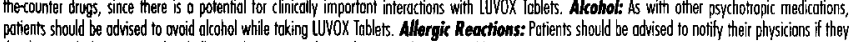

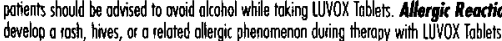

developo a 10st, hives,
loboratory Tosts

There are no specific loboratory tessts recommended.

Drug Interactions

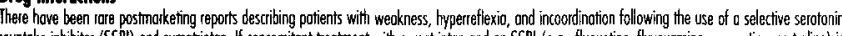

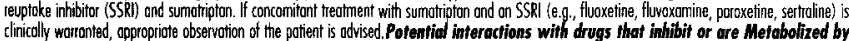

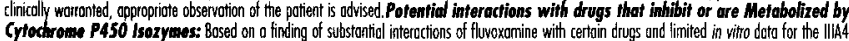

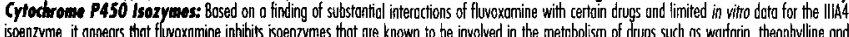

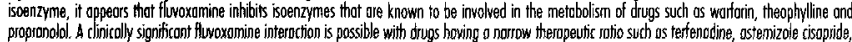

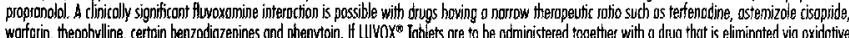

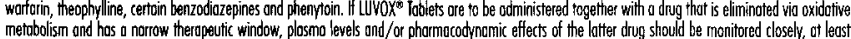

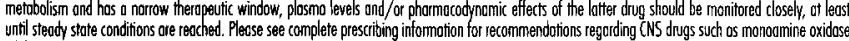

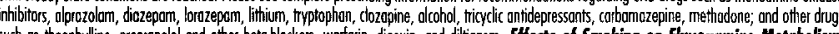

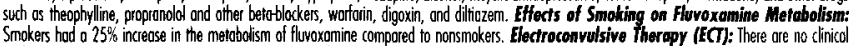

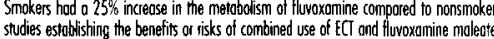

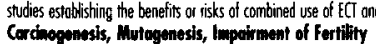

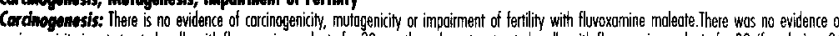

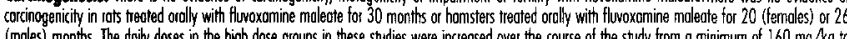

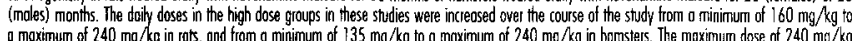
o maximum of $240 \mathrm{mg} / \mathrm{kg}$ in rots, and from a minimum of $735 \mathrm{mg} / \mathrm{kg}$ to 0 moximum of $240 \mathrm{mg} / \mathrm{kg}$ in hanstes. The maximum dose of $240 \mathrm{mg} / \mathrm{kg}$

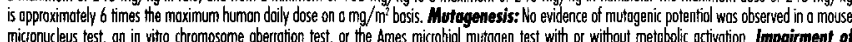

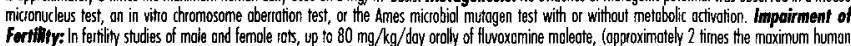

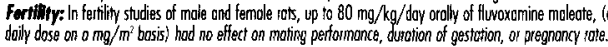

Prognemen

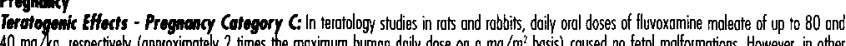

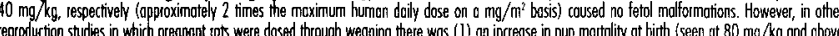

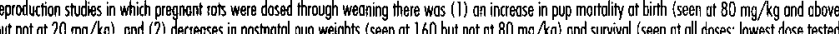

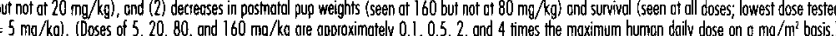

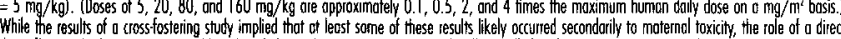

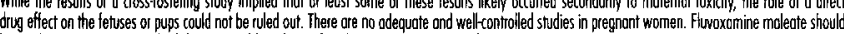

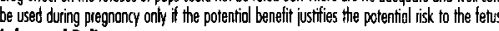

labor and Dolivery

Mursing Mothers

As tor mony yher drugs, flivoxomine is secetered in human blesst milk. The decision of whether to discontinue nusing of 10 discontinue the drug should

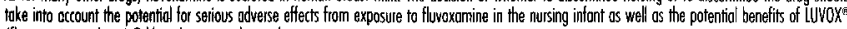

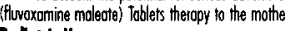

Podideric Use

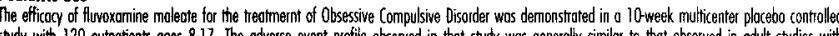

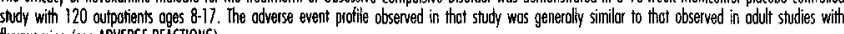

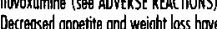

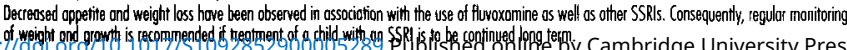

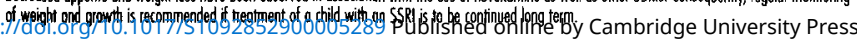

Geriatric Use

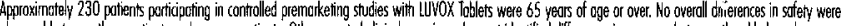
ouserved between these patients and younger petients. Other reponted clinical experience has not identitied differences in responssa between the eberty and younger

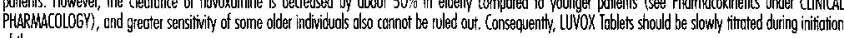
of theropy.

\section{Associoted with Discontinuation of Treatment}

Of the 1087 OCD and depressed potients treated with fluvoxamine maleate in controlled dinical triels conducted in North America, 22\% discontinued trectment due to an odverse event.

\section{Adverse events in OCD Pediatric Population}

In pediatic potients ( $(\mathrm{N}=57)$ treated with Luvox" Tablets, the overoll profile of adverse events is similar to that saen in odult studies. Other reactions which have been reported in two or more of the pediatic patients, end wele more frequent than in the placebo group. ( $N=63$ ) were: abnormal thinking, cough

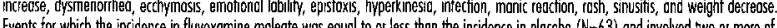

Events for which he incence study potients were: obdominal pain, aonormal dreams, fever, headache, nousea, nervousness, pain, pharyngitis and thinitis.

Incidence in Controlled Trials - Commonly Observed Adverse Events in Controlled Chinical Iriofs: Lurox Iatlets hove been studied in

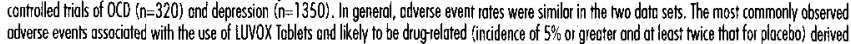
from Icthe 2 were: somer a posil of two studies involving only patients with OCD, the following additiono events were identified using the cbove rule: dry mouth, decreased libido,

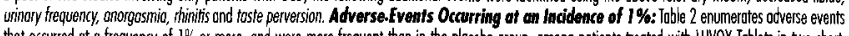
thot occurred of o frequency of $1 \%$ or more, ond were more frequent then in the placebo grouip, among patients treated with wirox Toblets in two short term placebo controlled $0 C 0$ ricks (10 week) ond depression triols ( 6 week) in which patients were dosed in a range of generally 100 to $300 \mathrm{mg} /$ day. This table shows the percentage of patients in each group who had of least one occurrence of an event of some time during their treotment. Reparted adverse events were classitied using o stondard COSTART bosed Dictioncry terminology. The prescriber should be oware that these tiguves cannot be used to predict

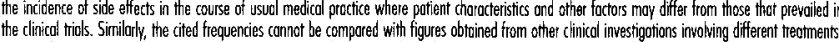
uses, and irvestigators. The cited figures, however, do provide the prescribing physicion with some bosis for estinnoting the relotive contribution of trug and

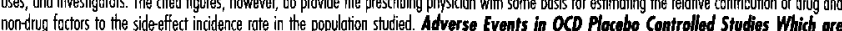
nondrug foctors to the side effect indidence rate in the population studied. Adverse Events in OCD Placebo Controlled Sivdies Which are Markedly Different (defined as at loast a fwo-fald difference) in Rate from the Poolod Evont Rotes in OCD and Dopression

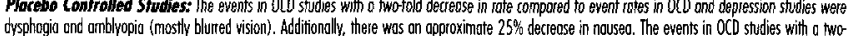
dysphigia ond amblyopia (mostly blurred vision). Additionally, there wos on approximate $25 \%$ decreose in nousea. The events in OCD studies with o two-

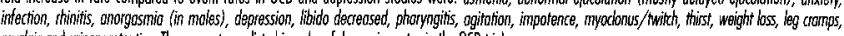

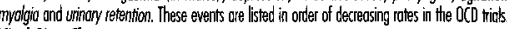

Vitul Sign Changes

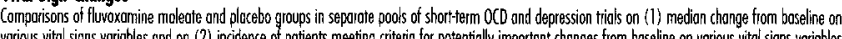

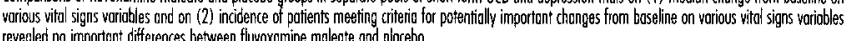
labereated no importent diff Changes

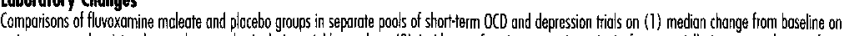

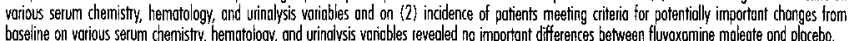

bCastine on vario

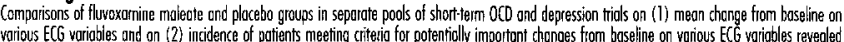
various $\mathrm{ECG}$ variables and on (2) incidence of patients meeting citering

Table 2: TREATMENT-EMERGENT ADVERSE EVENT INCIDENCE RATES BY BODY SYSTEM IN OCD AND DEPRESSION POPULATIONS COMBINED' (fllvoxemine [n=892] vs. placebo [n=778] by patients-perientage): BODY AS WHOLE: Heodoche (22 vs. 20) Asthenia (14 vs. 6); Fil Syndrome (3 vs. 2); (hills (2 vs. 1). CARDIOVASCULAR: Pelpitations (3 vs. 2). DIGESTIVE SYSTEM: Nouseo (40 vs. 14 )

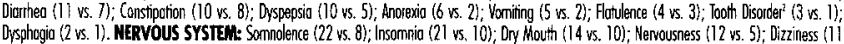

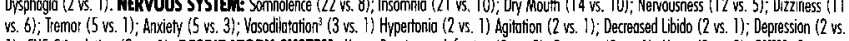

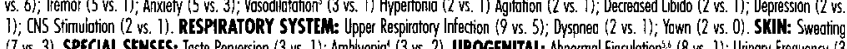

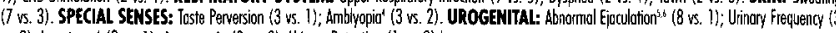
vs. 2); Impotence (2 vs. 1); Anorgasmia (2 vs. 0); Urinary Retention (1 ws. 0).

Events for which Alsvoxamine maleate indidence was equal to or less than plocebo are not listed in the toble above, but include the following: abdominal

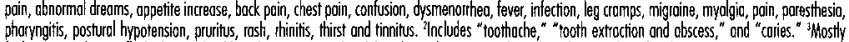

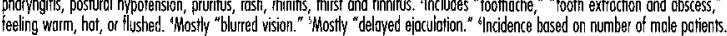

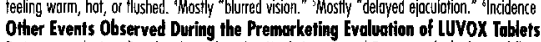

Dusing premorketing clinical trials conducted in North Americo and Europe, multiple doses of fuwoxomine moleate were administered for 0 combined total of 2737 patient expcssures in potients sufffering OCD or Major Depressive Disorder. Un:toward events associoted with this exposure were recorded by clinicol investigoters using descriptive terminology of their own cloosing. Consequenty, it is not possible to provide o meaningtul estimate of the proportion of

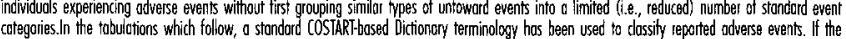

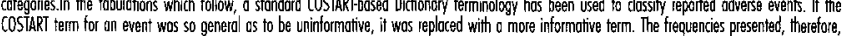

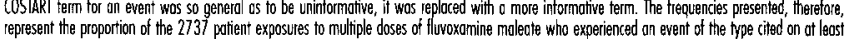

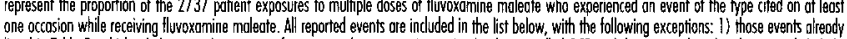

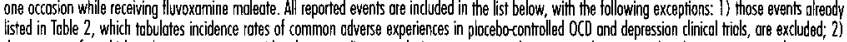
thase events for which o druy couse was considered renote (i.e., neoplasia, gostrointestinol cotcinoma, herpes simpiex, heepes zoster, opplication site leaction, and unintended pregnancyl are omitred; and 3) events which wele (epported in only one patient and judged to not be potentiolly serious are not inctuded. It is important to emphosize thot, athough the events reported did occur during treatment with fluvoxomine maleate, o coussol relationship to wsing the following definitions: trequent adverse events are defined os those occurring on one or more occosions in ot least $1 / 100$ patients, infrequent

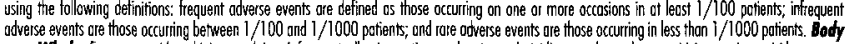

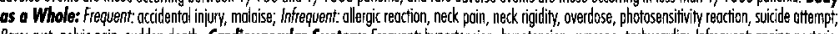

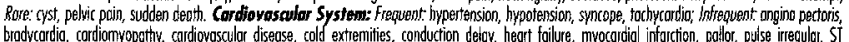
bradycardia, cordiomyopathy, cardiovasalar disease, cold extremities, conduction delay, heart failure, myocardial inforction, pallor, pulse irregular, ST segment changes; Rare: AV block, cerebrovasculor occident, coronary artery dissose, embolus, pericorditis, phlebitis, pulmonary infarction, supraventricular

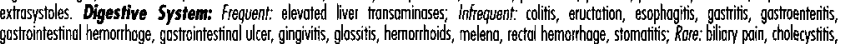

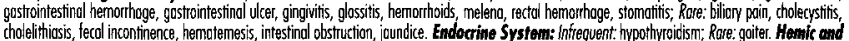

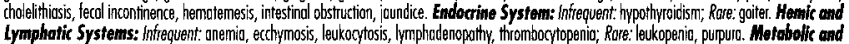

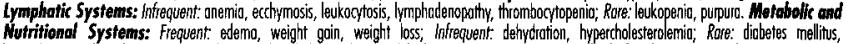

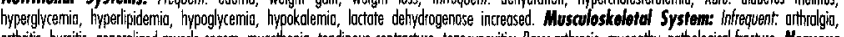

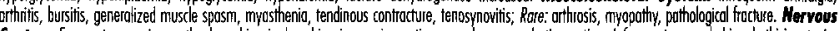

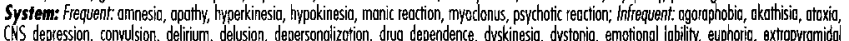

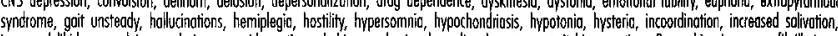
increased libido, neuralgio, pardysis, paranoid reaction, phobia, psychosis, sleep disorder, stupor, twitthing, vertigo; Rore: okinasia, coma, fibrillations, mutism, obsessions, reflexes decreased, slurred speech, tordive dyskinesia, ;orticollis, trismus, withdiawoi syndrome. Respirotory Systems: Frequent, cough increosed, sinusitis; Infrequent; osthma, bronchitis, epistoxis, hoorseness, hyperventilatien; Rore: opnea, congestion of upper airwoy, hemooptysis,

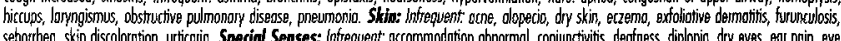

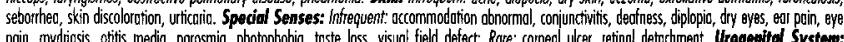

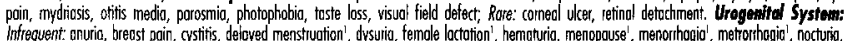

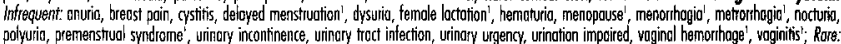
polyuria, premenstual syndrome', urinary in
kidney colculus, hematossermia', digurio.

Based on the number of females. "Bosed on the number of miles.

Non-US Postmarketing Reports

Voluntary reports of adverse events in potients toking LWWOX Toblets that have been received since market introduction and ore of unknown cousa relationship to LWWOX Tablets use include: toxic epidermal necrolysis, Stevens:Jotnnson syndrome, Henoch-Schoenlein purpuro, bullous eruption, priapism,

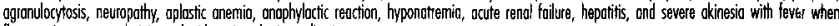
tuvoxemine was co-ocministered with antipsychotic medicotion.

CAUTION: Federal low prohibits dispensing without" prescription

8 E $1252 \operatorname{Rev} 3 / 97$

Reference: 1. Data on file, Solvay Pharmaceuticals, Inc.

Pharmacia\&Upjohn

Solvay

Pharmaceuticals 


\section{EFFECTIVE FIRST-LINE SSRI THIERAPY FOR OCD...}

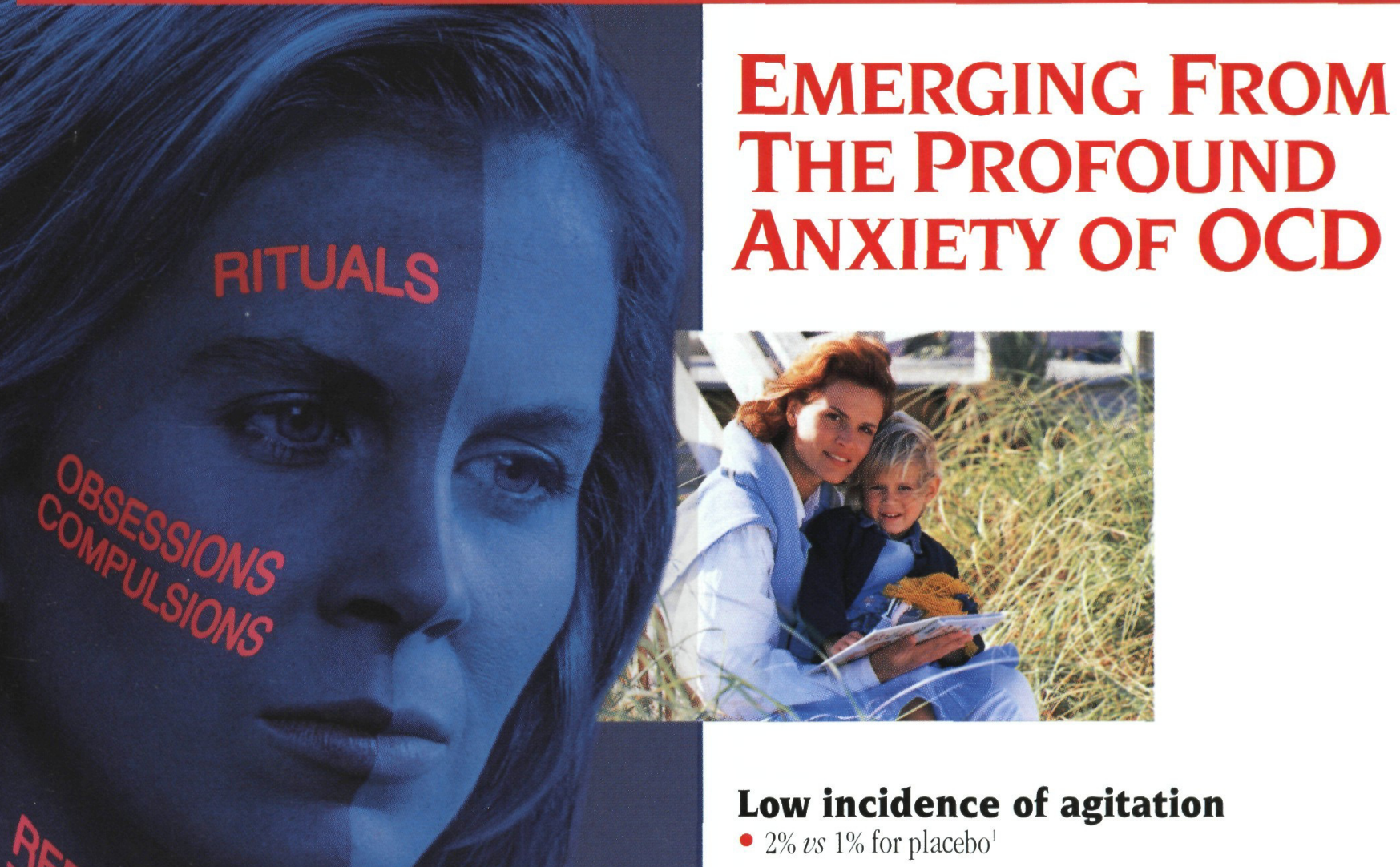

\section{Low incidence of sexual dysfunction'}

- LUVOX ${ }^{\circledast}$ Tablets us placebo*: decreased libido $2 \%$ vs 1\%; delayed ejaculation $8 \%$ vs 1\%; anorgasmia $2 \%$ vs $0 \%$; impotence $2 \%$ vs $1 \%$

\section{Favorable tolerability profile}

- Relatively low incidence of anticholinergic side effects in controlled trials of OCD and depression. LUVOX ${ }^{\text {(i) Tablets }}$ vs placebo: dizziness $11 \%$ us $6 \%$; constipation $10 \%$ vs $8 \%$; dry mouth $14 \%$ vs $10 \%$

- For adults, the most commonly observed adverse events compared to placebo were somnolence $22 \%$ vs $8 \%$; insomnia $21 \%$ vs $10 \%$; nervousness $12 \%$ vs $5 \%$; nausea $40 \%$ vs $14 \%$; asthenia $14 \%$ vs $6 \%$

- Adverse events in children and adolescents were similar to those observed in adult studies. The most commonly observed adverse events compared to placebo were: agitation $12 \%$ vs $3 \%$; hyperkinesia $12 \%$ vs 3\%; depression $5 \%$ vs $0 \%$; dysmenorrhea $7 \%$ vs 3\%; flatulence $5 \%$ vs $0 \%$; rash $7 \%$ vs 3\%

- Concomitant use of LUVOX ${ }^{\circledast}$ Tablets and monoamine oxidase inhibitors is not recommended'

Please see brief summary of prescribing information on adjacent page. 